\title{
REVIEW | Hip-Hop in Europe: Cultural Identities and Transnational Flows
}

Sina A. Nitzsche and Walter Grünzweig Eds.

Zürich: LIT Verlag, 2013

ISBN 9783643904133 (PB)

James Cox

Macquarie University

james.cox@students.mq.edu.au

Sina Nitzsche and Walter Grünzweig's new edited collection explores the multitude of ways hip-hop has been taken up across Europe. Through six sections, the collection explores the genre in nineteen European countries and represents the first time that such a collection has been compiled. Whilst being based in a series that examines transnational and transatlantic American studies (Transnational and Transatlantic American Studies, Volume 13), this compendium demonstrates the wide variety of approaches that can be found in hip-hop studies. The collection examines hip-hop in Europe through a transnational perspective. In this way, it picks up where Mitchell's Global Noise: Rap and Hip-Hop Outside the U.S. (2001) left off, by further examining the transnational connections found in hip-hop across Europe. Whereas Mitchell's (2001) work looked at hip-hop around the world, this collection's European emphasis allows for a more focused examination of the multidirectional flows of hip-hop; not just from the US to Europe, but also back to North America, and the multiple flows within European contexts.

In her introduction, Nitzsche notes that the publication has three objectives: firstly, to introduce a European perspective into the contemporary discussion of hip-hop; secondly, to demonstrate the multidirectional flows within global hiphop; and finally, to contribute to the literature on transnationalism by using hiphop in Europe as a case study. These three aims are largely met throughout the 
volume. The collection's geographical focus provides a welcome European presence to current hip-hop scholarship. Indeed, many of the countries in the collection are otherwise underrepresented, and the chapters that examine the genre in countries that used to be behind the Iron Curtain are a great example of this. Little has been written in English about hip-hop in countries like BosniaHerzegovina (Kovač), the Czech Republic (Oravcová), Hungary (Szabó Gilinger), Poland (Antoszek), Romania (Doboş) and Russia (Ivanov); the chapters on each of these locations give an important insight into the ways in which hip-hop has been taken up in these post-communist states. What is common across all three is that hip-hop, despite its US origins, has been made local to each context. As Ivanov notes in his chapter, hip-hop in Russia might have initially been seen as a fashion, and an attempt to copy the "cool" and "forbidden" western styles, but it has quickly begun to coalesce into a culture and gain mainstream Russian attention. The examination of the genre in former communist states demonstrates just how similar and at the same time just how different the genre can be in countries that are geographically close.

The final section only contains one chapter, but it is an important one. Matthäus Ochmann's exploration of authenticity in international hip-hop provides a welcome update to the debates on this topic in the genre outside of America, noting the importance of notions of authenticity within global scenes, and calling for an expanded examination, that goes beyond the common discussions of semantic dimensions. Ochmann draws on much of the key literature on authenticity in hip-hop in this analysis and as such, this chapter represents an important summation of, and direction for, this aspect of hip-hop studies.

Overall, this collection represents a useful contribution to the field of hip-hop studies, especially for those who study the genre outside of the US. The topics covered in the collection demonstrate that hip-hop around the world often operates in very similar contexts, but with unique and specific differences brought about by the culture within which hip-hop has taken root. The volume's focus on countries in Europe that have previously not had much attention from hip-hop scholarship is a welcome addition to the field, particularly those eastern European nations mentioned above. As the first collection of its kind that specifically focuses on hip-hop in Europe, the book allows for comparisons of the genre between geographically close neighbors; an aspect of hip-hop scholarship that rarely happens in this way. Overall, the collection presents an extremely important contribution to global hip-hop scholarship, and European hip-hop scholarship specifically.

\section{Reference}

Mitchell, T. Ed. 2001. Global Noise: Rap and Hip-Hop Outside the USA Middletown, CT: Wesleyan University Press. 